\title{
Government bond market dynamics and sovereign risk: systemic or idiosyncratic?
}

Citation for published version (APA):

Bicu, A. C., \& Candelon, B. (2012). Government bond market dynamics and sovereign risk: systemic or idiosyncratic? METEOR, Maastricht University School of Business and Economics. METEOR Research Memorandum No. 032 https://doi.org/10.26481/umamet.2012032

Document status and date:

Published: 01/01/2012

DOI:

10.26481/umamet.2012032

Document Version:

Publisher's PDF, also known as Version of record

\section{Please check the document version of this publication:}

- A submitted manuscript is the version of the article upon submission and before peer-review. There can be important differences between the submitted version and the official published version of record.

People interested in the research are advised to contact the author for the final version of the publication, or visit the DOI to the publisher's website.

- The final author version and the galley proof are versions of the publication after peer review.

- The final published version features the final layout of the paper including the volume, issue and page numbers.

Link to publication

\footnotetext{
General rights rights.

- You may freely distribute the URL identifying the publication in the public portal. please follow below link for the End User Agreement:

www.umlib.nl/taverne-license

Take down policy

If you believe that this document breaches copyright please contact us at:

repository@maastrichtuniversity.nl

providing details and we will investigate your claim.
}

Copyright and moral rights for the publications made accessible in the public portal are retained by the authors and/or other copyright owners and it is a condition of accessing publications that users recognise and abide by the legal requirements associated with these

- Users may download and print one copy of any publication from the public portal for the purpose of private study or research.

- You may not further distribute the material or use it for any profit-making activity or commercial gain

If the publication is distributed under the terms of Article $25 \mathrm{fa}$ of the Dutch Copyright Act, indicated by the "Taverne" license above, 
Andreea Bicu, Bertrand Candelon

Government bond market dynamics and sovereign risk: systemic or idiosyncratic?

$\mathrm{RM} / 12 / 032$

\section{METEOR}

Maastricht University School of Business and Economics

Maastricht Research School of Economics

of Technology and Organization

P.O. Box 616

NL - 6200 MD Maastricht

The Netherlands 


\title{
Government bond market dynamics and sovereign risk:
}

\section{systemic or idiosyncratic?}

\author{
Andreea Bicu* and Bertrand Candelon ${ }^{\dagger}$
}

June 20, 2012

\begin{abstract}
This paper investigates the comovement of long-term government bond yields in the Eurozone. The methods used for identifying common trends and common cycles are cointegration and SCCF (serial correlation common feature). These low and high frequency comovement analyses based on asymptotic critical values fail to identify the almost perfect convergence of 10 year sovereign bond yields. After adjusting for heteroscedasticity we find strong evidence for similar cyclical movements and a reduced number of "common cycles" for two separate groups (core and periphery). This confirms the hypothesis that in the European EMU (Economic and Monetary Union) the perceived risk of member states has converged. Based on the explanatory power of common and idiosyncratic components, we observe that sovereign yields are mainly driven by common risk factors and to a reduced degree by country specific characteristics. We investigate wether our results are affected by the recent sovereign debt crisis. With some notable exceptions, we find only small declines in the explanatory power of the common component. In line with recent literature on increased general risk aversion during times of stress, some policy implications for the common currency area are formulated.
\end{abstract}

Keywords:Euro Area; Sovereign bond yields; Co-integration; Serial correlation common feature JEL Classification: E43; G12

\footnotetext{
*Maastricht University, Department of Economics, PO Box 616, MD 6200, Maastricht, The Netherlands, Tel.: +31433883653; Email: a.bicu@maastrichtuniversity.nl

$\dagger$ Maastricht University, Department of Economics, PO Box 616, MD 6200, Maastricht, The Netherlands, Tel.: +31433883442; Email: b.candelon@maastrichtuniversity.nl
} 


\section{Introduction}

It is well known that the first 10 years of the EMU (Economic and Monetary Union) brought about almost perfect synchronization in the Euro area sovereign bond market, with country differences in yields at almost zero levels. This however changed around September 2008 when spreads with respect to Germany started increasing. In November 2011, the risk premium attached to Greek sovereign borrowing was around 16 p.p. above Germany. Following the recent crisis, a number of papers have tried to understand the divergence of sovereign bond yields. Beber et al. (2009) attribute most of the widening in spreads to liquidity factors and credit quality. In times of increased risk aversion investors rebalance their portfolios and substitute risky assets for more creditworthy bonds ("flight to quality"). The contribution of such factors depends on the maturity of the instrument considered and is heterogenous in the sample of European countries. Sgherri and Zoli (2009), among others, bring into discussion the (in)ability of markets to price the risk of sovereign bonds, i.e. differentiate through properly quantifyied risk premiums before 2008. They note that while there were indeed significant macroeconomic differences between the member countries prior to the start of the recent financial crisis, the level of yields never deviated from each other by more than 1 p.p. Sgherri and Zoli (2009) try to explain the reason behind the recent over-penalizing reaction of the markets. The authors estimate a common dynamic factor and quantify the importance of such a factor and other idiosyncratic variables in explaining sovereign spreads. Attinasi et al. (2009) and von Hagen et al. (2011) use panel techniques to calculate the relative contribution of liquidity and fiscal variables in addition to a common risk aversion proxy. Metiu (2011) also uses proxies for international risk factors in a study of EMU debt crisis and contagion effects.

In the same direction, we try to disentangle the impact of idiosyncratic and common components at both low and high frequency. Our approach resembles to some degree Sgherri and Zoli (2009), as we do not use a proxy but rather identify the driving forces endogenously from the dataset. However, our aim is to characterize the data through an observable factor structure, i.e. linear combinations that explain a significant percentage of the variation. This approach leads to a more useful description of the time series since we can clearly identify the drivers of the dynamics within our chosen sample and their relative strength in the adjustment process. We focus solely on common components and do not quantify the impact of fiscal or other national factors as in the above cited papers. We feel that this direction has already been extensively explored and we would rather like to offer insights into a different identification procedure of the common components and their explanatory power.

Cointegration testing is a standard statistical approach used to characterize driving trends in the data. For a set of $N$ variables, detecting one common trend in the dynamics of the system (i.e. a cointegration rank of $N-1$ ) could be interpreted as a "convergence process" driven by economic and monetary integration. A simple graphical analysis indicates almost no differentiation in the levels of long term sovereign bond yields before 2008. Moving beyond such an analysis, one can test for the presence of similar cyclical variation. Vahid and Engle (1993) use the concept of serial correlation common features (SCCF) to describe common cyclical movements and linear combinations of the data that no longer exhibit predictable patterns. In an integrated bond market yields should react similarly to common 
news (Ehrman et al. (2011)), which implies similar short run movements. A contribution of our paper is adapting both these tests to the presence of heteroskedasticity in the data. In this direction, we use appropriate bootstrap corrections throughout the testing procedure. While the properties of the bootstrap in cointegration testing have been analyzed by a number of authors (Cavaliere et al. (2010), Swensen (2006) inter alia), to our knowledge we are the first to extend this to a model with cointegration and SCCF.

Once common cycles and trends are identified, it is also of interest to see how much of the cyclical behavior is explained by common dynamics. When the increase in sovereign yields is driven mainly by factors common to a group of countries we can conclude that idiosyncratic characteristics play only a minor role. Understanding the relative contribution of country specific and common drivers can help policymakers decide on appropriate measures when dealing with high borrowing costs. An idiosyncratic shock fostered by worsening fundamentals may be accommodated through fiscal/financial/monetary discipline, depending on the original source of market concern. If, on the other hand, higher borrowing costs are a reaction of increasing global risk aversion and contagion then strict policy measures will weaken a fragile economy even more without bringing about the intended benefits. Such questions are of increased importance especially when analyzing the divergence of yields during the most recent years of our sample. It is interesting to observe how strongly our results are affected by these last observations.

Based on the results obtained we can contrast our approach to others used in the literature. Any direct comparison should however be made with caution. First of all, different measurements of common components are expected to reach different conclusions as they do not always exploit the same statistical properties in the data. Secondly, while most papers use spreads with respect to an anchor country (usually Germany) we look directly at the levels and changes in sovereign borrowing costs. Spreads are generally considered to be stationary throughout the literature cited in this paper. However, we calculate unit root tests and find that in most cases they are still I(1) processes.

This paper is organized as follows. Section 2 presents in more detail the relevant literature on the recent sovereign yields divergence and SCCF theory while data description and statistical properties of the interest rate series (stationarity, cointegration) are dealt with in Section 3. In section 4 we discuss different approaches for the testing procedure and introduce the bootstrap in the SCCF reduced rank model. Section 5 deals with estimation/identification of common components and their explanatory power in our dataset. We investigate how results change during the sovereign debt crisis in Section 6 . Section 7 concludes.

\section{Related Literature}

There is a a rich literature disentangling the effects of macroeconomic variables on sovereign risk and borrowing costs. Sovereign bond yields are a direct indicator of how a country's creditworthiness is perceived by the market and the period around the introduction of the Euro represents a unique sample for analyzing such risk pricing. As Ardagna et al. (2007) point out, country specific fiscal indicators are expected to have a reduced influence after a common currency is introduced. Instead, measures of 
aggregate economic conditions should have a much increased driving power. This is the main economic reasoning behind common dynamics of sovereign bond yields and the convergence process following the introduction of the Euro.

When trying to explain sovereign yields and spreads w.r.t. Germany, most studies discuss two different channels: a country specific risk component (related to fundamentals, liquidity, fiscal position etc.) and a common risk variable (denoting international conditions and directly related to the openess/exposure of a country). Codogne et al. (2003) have found evidence of both mechanisms in the Eurozone, with strong differences among countries when quantifying their importance. One of the conclusions of their study is that spreads are mainly driven by a common factor, a measure of international risk proxied by the sovereign/corporate bond yield spread in the US. Sgherri and Zoli (2009) estimate a dynamic (unobservable) common component using Bayesian techniques. A graphical analysis indicates that the factor's fluctuations can capture both the observed convergence of yields before 2008 and the widening of spreads during the last 3 years. While the general direction of the dynamics is correctly encompassed, the explanatory power is very low. The common component explains only a negligible percentage (bellow 20 b.p.) of the observed spreads. Regarding the most recent crisis period, they conclude that the markets are reassessing macroeconomic instabilities and attaching a higher "price" on the lack of discipline. Von Hagen et al. (2011) offer similar results by noting that elasticities to deficit and debt differentials have increased by a factor of 3 to 4 and 7 to 8 respectively. Focusing solely on the sample 2007-2009, Attinasi et al. (2009) quantify the contribution of an international risk factor alongside country specific variables and find that more than half of the sovereign spreads can be attributed to common factors. In conclusion, these papers find a change in risk pricing based both on increased general risk aversion and deteriorating fundamentals.

There are without a doubt contagion effects in the Eurozone bond market. Testing for contagion offers some difficulties in empirical work as there are several definition of the term, each entailing different transmission channels and underlying mechanisms. Metiu (2011) focuses on the EMU sovereign debt crisis and uses proxies for international risk factors (Chicago Board Options Exchange Volatility IndexVIX, spread between Baa and Aaa corporate bonds). He finds that a significant part of sovereign risk is caused by a general change in the investors' attitude, similar to the results of the previously cited papers. There are clear signs of contagion, with causal links starting from Greece and gradually moving towards different groups of countries. Metiu (2011) identifies shifts in the source of contagion and emphasizes the disruptive effects of sovereign weaknesses in open economies with integrated bond markets.

The econometric approach that we use here aims at disentangling the common and idiosyncratic components in the data. Describing correlations between a series of variables, we look at long run driving trends (cointegration) alongside with short-run comovements. Vahid and Engle (1993) introduce the concept of serial correlation common features (SCCF), i.e. characteristics found individually in each time series and shared by the entire multivariate data set. Such a feature will be common if there exists a linear combination that eliminates the existing characteristic and that is therefore an innovation w.r.t. past information. Finding such combinations leads to identifying similar short run movements and to a more parsimonious description of the data. SCCF among first differences of I(1) variables signals that 
after removing the trends the left over dynamic behavior (cycles) are also moving together. As mentioned before, short-run co-movements are a likely result in a monetary union since area wide shocks should lead to similar country-level responses. Intuitively, there is a direct relationship between the concepts of SCCF and cointegration: finding linear combinations that eliminate a statistical property found in all of the individual time series. Identifying such properties of the data can be translated into a reduced rank problem: since common behavior exists, we can reduce the dimension of the system representation and parameter space without a loss of information.

$$
\Delta y_{t}=\alpha \beta^{\prime} y_{t-1}+\sum_{i=1}^{p-1} \Gamma_{i} \Delta y_{t-i}+\epsilon_{t}
$$

The starting point for our analysis is the $\operatorname{VECM}(\mathrm{p}-1)$ representation (1), where $y_{t}$ is an n-dimensional process and $\beta_{n * r}$ the matrix spanning the cointegration space. When dealing with short run dynamics of cointegrated I(1) variables, one has to take into account the error correction term when defining the past information set. SCCF implies that $\alpha$ (matrix of adjustment coefficients) and $\boldsymbol{\Gamma}=\left[\Gamma_{1}, \Gamma_{2}, \ldots, \Gamma_{p-1}\right]$ (short run dynamics) share the same left null space. Since this implies very strict restrictions for the VECM matrices, Hecq et al. (2006) argue for a less constrained version called the Weak Form (WF). The WF is based on linear combinations after adjusting for the long-run relationships determined. In both the SF (SCCF) and the WF, $\tilde{\beta}_{n * s}$ represents the cofeature matrix.

$$
\begin{gathered}
S C C F / S F: \tilde{\beta}^{\prime} \Delta y_{t}=\tilde{\beta}^{\prime} \epsilon_{t} \\
W F: \tilde{\beta}^{\prime}\left(\Delta y_{t}-\alpha \beta^{\prime} y_{t-1}\right)=\tilde{\beta}^{\prime} \epsilon_{t}
\end{gathered}
$$

Finding a cointegrated-SCCF structure in the data indicates that there exist common trends and common cycles. In a system of cointegrated variables and no determinstic components, these can be identified using the multivariate Beveridge-Nelson decomposition (Beveridge and Nelson (1981)):

$$
y_{t}=C(1) \sum_{i=1}^{t} \epsilon_{i}+C^{*}(L) \epsilon_{t}
$$

Cointegration implies that the matrix $\mathrm{C}(1)$ is of reduced rank $n-r$, while SCCF leads to similar rank properties for the transitory component of the decomposition, i.e. $\operatorname{rank}\left(C^{*}\right)=n-s$. The Gonzalo and Granger (1995), Beveridge Nelson and Vahid and Engle (1993) decompositions coincide whenever $r+s=n$. In this special case a system of cointegrated variables with common features can be decomposed into $n-r$ common trends $\tilde{\beta}^{\prime} y_{t}$ and $n-s$ common cycles $\beta^{\prime} y_{t}$.

$$
y_{t}=\tilde{\beta}\left(\tilde{\beta}^{\prime} \tilde{\beta}\right)^{-1} \tilde{\beta}^{\prime} y_{t}+\beta\left(\beta^{\prime} \beta\right)^{-1} \beta^{\prime} y_{t}+\epsilon_{t}
$$

Cubadda (1999) points out that the presence of SCCF vectors should not be interpreted as signs of comovements at the business cycle frequency. His frequency domain analysis does not challenge such an analysis but rather offers a caution note on how the results should be interpreted.

Our analysis is also driven by concerns regarding misspecifications in such statistical models. Most testing procedures rely on very strict assumptions of normality and homoskedasticity and are most of 
the times invalid when the data departs from these assumptions. We take these issues into consideration throughout our analysis since the majority of economic/financial time series do not follow a normal, wellbehaved process. Since the SCCF analysis used to identify common short run movements is conditional on the cointegration matrix and rank, incorrect identification in the first step can invalidate the results obtained. Anderson and Vahid (2010) report forecasting performance with a reduced rank VAR/VECM when the cointegrating and SCCF ranks are misspecified. They find that overestimating $r$ (most likely outcome when departing from normality and homoscedasticity) has a negative effect on long-run forecasts. The difference between overspecification and underspecification is, not surprisingly, dependent on the strength of the cointegrating relationship: when error correction mechanisms are extremely powerful it is more detrimental to opt for a underestimated cointegrating rank $r$. Misspecifications of $s$ cause relatively less serious issues, but non-negligible especially for short horizons.

\section{Data and initial analysis}

The data for monthly 10 year government bond yields is taken from the IMF database for the interval 1990:M1-2011:M10. The countries in out dataset are: Austria, Belgium, Finland, France, Germany, Ireland, Italy, Netherlands, Portugal and Spain. Before considering possible commonalities, we first investigate whether the individual series have a specific time dependent structure. Table 1 indicates the AR behavior for levels and first differences, with most series exhibiting an autoregressive behavior of order two. This result supports a common feature analysis: all yields exhibit an autoregressive pattern with the same lag structure.

Table 1: AR behaviour

\begin{tabular}{ccc}
\hline Country & Level & First difference \\
\hline Austria & 2 & 3 \\
Belgium & 2 & 2 \\
Finland & 2 & 2 \\
France & 2 & 2 \\
Germany & 2 & 2 \\
Greece & $2 / 6$ & $1 / 4$ \\
Ireland & 2 & 2 \\
Italy & 3 & 2 \\
Netherlands & 2 & 2 \\
Portugal & 3 & 2 \\
Spain & 2 & 2 \\
\hline
\end{tabular}

Next, the time series are checked for unit roots using the ADF test. They are found to be I(1). Not surprisingly we obtain limit results for the southern countries, Finland and Ireland. Before the year 2000 the downward trending behavior is very strong, with the ADF test statistic very close to the I(1) critical value for first differences. We also calculate unit root tests for spreads w.r.t. Germany and find that 
in most cases they are still $\mathrm{I}(1)$ processes, contrary to the stationarity assumption of most studies using sovereign spreads.

Table 2: ADF - Yields

\begin{tabular}{ccccc}
\hline Country & $y$ & lags & $\Delta y$ & lags \\
\hline Austria & $\mathrm{I}(1)$ & 3 & $\mathrm{I}(0)$ & 2 \\
Belgium & $\mathrm{I}(1)$ & 3 & $\mathrm{I}(0)$ & 2 \\
Finland & $\mathrm{I}(1)$ & $6 / 1$ & $\mathrm{I}(0)$ & 5 \\
France & $\mathrm{I}(1)$ & 1 & $\mathrm{I}(0)$ & 0 \\
Germany & $\mathrm{I}(1)$ & 5 & $\mathrm{I}(0)$ & 2 \\
Greece & $\mathrm{I}(1)$ & $10 / 1$ & $\mathrm{I}(1) / \mathrm{I}(0)$ & $9 / 0$ \\
Ireland & $\mathrm{I}(1)$ & $3 / 2$ & $\mathrm{I}(0)$ & $2 / 1$ \\
Italy & $\mathrm{I}(1)$ & $3 / 1$ & $\mathrm{I}(0)$ & $2 / 1$ \\
Netherlands & $\mathrm{I}(1)$ & 1 & $\mathrm{I}(0)$ & 2 \\
Portugal & $\mathrm{I}(1)$ & 1 & $\mathrm{I}(0)$ & $7 / 0$ \\
Spain & $\mathrm{I}(1)$ & 3 & $\mathrm{I}(0)$ & 2 \\
\hline
\end{tabular}

Table 3: ADF - Spreads

\begin{tabular}{ccccc}
\hline Country & $y$ & lags & $\Delta y$ & lags \\
\hline Austria & $\mathrm{I}(0) / \mathrm{I}(1)$ & $0 / 9$ & $\mathrm{I}(0)$ & 0 \\
Belgium & $\mathrm{I}(1)$ & 4 & $\mathrm{I}(0)$ & 3 \\
Finland & $\mathrm{I}(1)$ & $6 / 1$ & $\mathrm{I}(0)$ & 1 \\
France & $\mathrm{I}(1)$ & 1 & $\mathrm{I}(0)$ & 0 \\
Greece & $\mathrm{I}(1)$ & 10 & $\mathrm{I}(1)$ & 9 \\
Ireland & $\mathrm{I}(1)$ & $3 / 2$ & $\mathrm{I}(0)$ & $2 / 1$ \\
Italy & $\mathrm{I}(1)$ & $3 / 1$ & $\mathrm{I}(0)$ & $2 / 1$ \\
Netherlands & $\mathrm{I}(1)$ & 1 & $\mathrm{I}(0)$ & 2 \\
Portugal & $\mathrm{I}(1)$ & 1 & $\mathrm{I}(0)$ & $7 / 0$ \\
Spain & $\mathrm{I}(1)$ & 2 & $\mathrm{I}(0)$ & $2 / 1$ \\
\hline
\end{tabular}

The next step in our analysis is cointegration testing. We use the Johansen $(1988,1991)$ trace test and the tabulated critical values. Cointegration testing shows a rank of $r=8$ for the complete dataset $(n=11)$. Results for pairs and subgroups of countries also offer some interesting results. We consider two separate groups: Austria-Belgium-France-Germany-Netherlands (core countries) and Portugal-IrelandItaly-Greece-Spain (PIIGS). The complete pairwise cointegration results are available in the Appendix. The size and power properties of the trace test have been investigates in numerous papers. Cheung and Lai (1993) show that in small samples the test is biased towards finding cointegration. Other Monte Carlo analyses in the paper find that the trace test is robust to overparametrization but much more sensitive to underparametrization. This should be taken into account when choosing the lag length. Regarding non- 
normal errors, Cheung and Lai's results show robustness to excess kurtosis but significant size distortions when skewness in present.

In the presence heteroskedasticity and taking into account the poor size and power properties of the test as discussed above, we proceed with bootstrapping the trace test. We follow the sequential test procedure as described in Swensen (2006) and adjust for heteroskedasticiy as done by Cavaliere et al. (2010a). This requires estimating an unrestricted $\operatorname{VAR}(p)$ and the cointegrated $\operatorname{VAR}(\mathrm{p}) / \operatorname{VECM}(\mathrm{p}-1)$ under the specified null hypothesis and using a wild bootstrap procedure for the residual resampling. The trace statistic initially developed by Johansen $(1988,1991)$ is constructed under the assumption of i.i.d. residuals. Lee and Tse (1996) are the first authors to show that the test suffers from size distortions when we depart from this (very strong) assumption. Since the following SCCF analysis depends on a correct rank determination, inference on the cointegrating behavior of the variables should be carefully preformed. The sequential testing procedure for $H_{0}: r=\bar{r}$ against $H_{a}: r=n$ (unrestricted) uses $B=999$ and follows 4 steps:

1. Using the estimated $\hat{\epsilon}_{t}$ from the unrestricted model and an independent $\mathrm{N}(0,1)$ sequence $\left\{w_{t}\right\}$ generate $\mathrm{T}$ bootstrap residuals $\epsilon_{t}^{b}=\hat{\epsilon}_{t} w_{t}$;

2. Reconstruct the bootstrap sample $\Delta y_{t}^{b}$ using the above defined residuals, $\hat{\alpha} \hat{\beta}$ from the estimation under the null hypothesis $r=\bar{r}$ and $\hat{\Gamma}$ from the unrestricted model;

3. Calculate the bootstrap trace statistic from the pseudo-sample;

4. Repeat steps 1, 2 and 3 B times and obtain bootstraped p-values.

Although deterministic terms do appear in the $\operatorname{VECM}(\mathrm{p}-1)$ estimation and trace test, no deterministic terms are used to reconstruct the pseudo-data. Cavaliere et al. (2010a) point out that this procedure is equivalent to adding the estimated deterministic terms (constant from restricted, trend from unrestricted). We have also found no significant differences and opted for the simplified model. In a a more recent paper, Cavaliere et al. (2010b) argue for using all the parameters of the VECM estimated under the null when reconstructing the bootstrap samples.

We continue our analysis with two subgroups of countries: core (Austria, Belgium, France, Germany, The Netherlands) and periphery (Portugal, Ireland, Italy, Greece, Spain). We add Germany to this last group as we feel like its sovereign yield is representative for all the other interest rates included in the first sample. While we do offer some results for Finland, we disregard this country from our sample from this point onwards. The results of the bootstrap procedure are summarized in the tables bellow.

Table 4: Cointegration: Aut-Bel-Fr-Ger-Ned $(p=7, r=1)$

\begin{tabular}{llllll}
\hline Rank & Trace & Asymptotic 5 & p-value & Bootstrap & p-value \\
0 & $135.45^{* *}$ & 76.81 & 0.000 & 112.9 & 0.001 \\
1 & 47.08 & 53.94 & 0.182 & 85.53 & 0.563 \\
2 & 27.68 & 35.07 & 0.259 & 45.76 & 0.665 \\
\hline
\end{tabular}


Table 5: Cointegration: Fin-Ire-It-Por-Esp $(p=10, r=1)$

\begin{tabular}{llllll}
\hline Rank & Trace & Asymptotic 5 & p-value & Bootstrap & p-value \\
0 & $203.48^{*}$ & 76.81 & 0.000 & 211.15 & 0.065 \\
1 & 116.38 & 53.94 & 0.000 & 181.44 & 0.532 \\
2 & 57.22 & 35.07 & 0.000 & 120.72 & 0.704 \\
\hline
\end{tabular}

Table 6: Cointegration: Port-Ire-It-Esp-Ger: PIISG $(p=11, r=1)$

\begin{tabular}{llllll}
\hline Rank & Trace & Asymptotic 5 & p-value & Bootstrap & p-value \\
0 & $152.72^{* *}$ & 76.81 & 0.000 & 146.9 & 0.032 \\
1 & 77.09 & 53.94 & 0.000 & 97.74 & 0.305 \\
2 & 41.76 & 35.07 & 0.007 & 64.26 & 0.525 \\
\hline
\end{tabular}

Table 7: Cointegration: Port-Ire-It-Gre-Esp-Ger: PIIGSG $(p=11, r=2)$

\begin{tabular}{llllll}
\hline Rank & Trace & Asymptotic 5 & p-value & Bootstrap & p-value \\
0 & $276.35^{* * *}$ & 103.68 & 0.000 & 192.3 & 0.000 \\
1 & $147.64^{* *}$ & 76.81 & 0.000 & 145.8 & 0.041 \\
2 & 88.39 & 53.94 & 0.000 & 106.4 & 0.240 \\
3 & 48.71 & 35.07 & 0.000 & 71.85 & 0.513 \\
4 & 22.23 & 20.16 & 0.024 & 38.95 & 0.600 \\
\hline
\end{tabular}

The bootstrap offers very different results than what the asymptotic tests would imply. The critical values increase dramatically and, while for central Euro area the cointegration rank does not change, for the group of countries in Table 6 (Portugal, Ireland, Italy, Spain, Germany: PIISG) it decreases from 4 to 1 . At the $5 \%$ level we conclude that we have $r=1$ ( $n-r=4$ common trends) for both the core countries group and the peripheral member states with Germany (PIISG). After including Greece in this last group we find that the cointegration rank is 2, as indicated in Table 7. Greece appears to be adding a second long-run relationship while the number of driving trends remains $n-r=4$. Using a strict definition of "convergence" as a single factor pushing the system towards a common path, our results could already be interpreted as evidence against such process having taken place in the Eurozone. However, we do not interpret the existence of multiple trends as being contradictory to the convergence hypothesis. The long run movements of the bond yields are influenced by a series of macroeconomic and financial fundamental factors which are different for each country. Moving beyond long-run cointegration properties and continuing our study with an analysis of short-run movements in the yields allows us to detect common transmission mechanisms. We are interested in finding common cyclical variations and drawing conclusions about the magnitude of period to period changes. Before describing the common feature testing procedure we show pairwise correlations for our sovereign yields time series in first differences. A strong correlation coefficient is an indicator of cross-country interdependece and similarity in reaction to shocks. 
Table 8: Correlations of changes in sovereign bond yields $\Delta y_{t}$

\begin{tabular}{ccccccccccc}
\hline & aut & bel & fr & ger & ned & it & ire & por & esp & gre \\
aut & 1 & 0.892 & 0.890 & 0.920 & 0.945 & 0.563 & 0.682 & 0.488 & 0.667 & 0.222 \\
bel & 1 & 0.905 & 0.881 & 0.904 & 0.569 & 0.690 & 0.395 & 0.662 & 0.229 \\
fr & & & 1 & 0.903 & 0.921 & 0.641 & 0.710 & 0.431 & 0.721 & 0.196 \\
ger & & & & 1 & 0.967 & 0.529 & 0.660 & 0.428 & 0.617 & 0.190 \\
ned & & & & 1 & 0.573 & 0.682 & 0.440 & 0.655 & 0.169 \\
it & & & & & 1 & 0.565 & 0.443 & 0.816 & 0.179 \\
ire & & & & & & 1 & 0.507 & 0.674 & 0.442 \\
por & & & & & & & 1 & 0.491 & 0.386 \\
esp & & & & & & & & & 1 & 0.269 \\
gre & & & & & & & & & & \\
\hline
\end{tabular}

\section{Testing procedure}

\subsection{CCA and regression based test}

After identifying the stationarity properties of the time series and estimating the cointegration space, we continue with testing for common patterns in the short run parameters $\left(\Gamma_{i}\right)$. We restrict our analysis to a possible SCCF structure of the data, the Strong Form in Hecq et al. (2006). We start with the $\operatorname{VECM}(\mathrm{p}-1)$ representation from (1).

$$
\Delta y_{t}=\Pi y_{t-1}+\sum_{i=1}^{p-1} \Gamma_{i} \Delta y_{t-i}+\epsilon_{t}=\alpha \beta^{\prime} y_{t-1}+\sum_{i=1}^{p-1} \Gamma_{i} \Delta y_{t-i}+\epsilon_{t}
$$

As a testing procedure, we can proceed by performing a (partial) canonical correlation analysis between the two sets of variables $\Delta Y_{t}=\left[\Delta y_{1}, \ldots, \Delta y_{t}\right]$ and $W_{t-1}=\left[\Delta Y_{t-1}^{\prime}, \ldots, \Delta Y_{t-p+1}^{\prime}, Y_{t-1}^{\prime} \beta\right]^{\prime}$. Under a SF representation, the matrix $\Gamma^{*}$ is of reduced rank and can be further decomposed as $\tilde{\beta}_{\perp}^{\prime} * A^{\prime}$.

$$
\Delta y_{t}=\Gamma^{*} W_{t-1}+\epsilon_{t}=\tilde{\beta}_{\perp}^{\prime} A^{\prime} W_{t-1}+\epsilon_{i}=\tilde{\beta}_{\perp}^{\prime} F_{t-1}+\epsilon_{t}
$$

Equation 7 above shows that an SCCF structure can also be interpreted as an (observable) factor model, with $F_{t-1}=A^{\prime} W_{t-1}$. Centoni et al. (2007) offer some comparisons in between this representation and the general dynamic factor model and note that all dynamics beyond those explained through the identified factors $F_{t-1}$ will be unpredictable. The dimension of the cofeature space $s$ is identified by the number of zero canonical correlations. We use a two step approach and first determine $r$ and $\hat{\beta}$. Next, we use the estimated error correction term $Y_{t-1}^{\prime} \beta$ and all $(p-1)$ lags of $\Delta Y_{t}$ as the relevant past information set. The null hypothesis of at least $s$ common feature vectors, i.e. $n-s$ common dynamic factors is tested with a LR test $T_{1}=-T \sum_{i=1}^{s} \ln \left(1-\lambda_{i}\right)$ for each possible $s=1, \ldots, n-r$. The eignevalues used $\lambda_{1} \leq \lambda_{2} \leq \ldots \leq \lambda_{n-r}$ are the ordered squared partial canonical correlations of the system $\left\{\Delta y_{t}, W_{t-1}\right\}$. The LR statistics for $H_{0}: \operatorname{rank}(\tilde{\beta}) \geq s$ against $H_{a}: \operatorname{rank}(\tilde{\beta})<s$, or equivalently $H_{0}: \operatorname{rank}\left(\Gamma^{*}\right) \leq n-s$ against $H_{a}: \operatorname{rank}\left(\Gamma^{*}\right)>n-s$ follows a $\chi_{(v)}^{2}$ distribution, with $v=s(n(p-1)+r)-s(n-s)$ degrees of 
freedom. Significance at the 5/1\% level means that the probability of not rejecting an extra co-feature vector is less than $5 / 1 \%$. Note that in the SF there can be maximum $n-r$ common feature vectors, i.e. $r$ maximum "common cycles".

A second approach to identifying $\mathrm{s}$ is a regression based test in the context of instrumental variables. Engle and Kozicki (1993) offer a simple interpretation for such an analysis: are past values of the system able to offer statistically significant information about the future path of the linear combination $\tilde{\beta}^{\prime} \Delta y_{t}$ ? If a testing procedure can reject such predictable behavior, then one would conclude that $\tilde{\beta}^{\prime}$ is a vector that annihilates the common feature found in the series. Based on this intuition, an instrumental variable/GMM procedure seems appropriate. The validity of the orthogonality conditions between the residuals and past values of the system $\left(W_{t-1}\right)$ would indicate that indeed the IV/GMM estimator is able to identify a linear combination that does not share any common features with the past. The IV estimator is described bellow, with $\Delta X_{t}=\left[\Delta y_{2 t}, \ldots, \Delta y_{n t}\right]$ and $W_{t-1}=\left[\Delta Y_{t-1}^{\prime}, \ldots, \Delta Y_{t-p+1}^{\prime}, Y_{t-1}^{\prime} \beta\right]^{\prime}$ the set of instruments.

$$
\hat{\theta}_{I V}=\left(\Delta X^{\prime} W\left(W^{\prime} W\right)^{-1} W^{\prime} \Delta X\right)^{-1}\left(\Delta X^{\prime} W\left(W^{\prime} W\right)^{-1} W^{\prime} \Delta y_{1}\right)
$$

The test statistic for the orthogonality conditions between the linear combination $\Delta y_{1 t}-\Delta X_{t}^{\prime} \theta_{I V}$ is a test for overidentification, i.e. the $\mathrm{J}$ statistic of Hansen (1982) using the residuals $u_{t}=\Delta y_{1 t}-\Delta X_{t}^{\prime} \hat{\theta}_{I V}$.

$$
T_{2}=\left(u^{\prime} W\right)\left(\hat{\sigma}_{u}^{2} W^{\prime} W\right)^{-1}\left(W^{\prime} u\right)
$$

Candelon et al. (2005) point out that the CCA and the IV approaches described above suffer from severe size distortions when the model departs from the homoskedasticity assumption. Using different specifications for a $\operatorname{GARCH}(1,1)$ process, the rejection frequencies of both tests are well above the nominal size. The authors propose a test based on a robust GMM estimator using the structure of White's heteroskedasticity-consistent covariance matrix.

$$
\hat{\theta}_{G M M}=\left(\Delta X^{\prime} W\left(W^{\prime} B W\right)^{-1} W^{\prime} \Delta X\right)^{-1}\left(\Delta X^{\prime} W\left(W^{\prime} B W\right)^{-1} W^{\prime} \Delta y_{1}\right)
$$

, where $W$ and $\Delta X$ are defined as above and

$$
\begin{gathered}
\mathrm{B}=\left[\begin{array}{cccc}
u_{1}^{2} & 0 & \cdots & 0 \\
0 & u_{2}^{2} & \cdots & 0 \\
\vdots & & \ddots & \vdots \\
0 & 0 & \cdots & u_{T}^{2}
\end{array}\right] \\
T_{3}=\left(u^{*^{\prime}} W\right)\left(W^{\prime} B W\right)^{-1}\left(W^{\prime} u^{*}\right),
\end{gathered}
$$

The B matrix contains the squared residuals obtained using the instrumental variables estimator $\theta_{I V}$ from (8) and $u_{t}^{*}=\Delta y_{t}-\Delta X_{t}^{\prime} \hat{\theta}_{G M M}$. The authors find such an extension necessary when dealing with financial data during periods of turmoil and increased volatility. In a simulation study with a bivariate GARCH(1,1) process, we find that the White adjusted GMM test has good size and power properties. Simulation results are not presented here as they are almost identical to the ones presented in Candelon 
et al. (2005). Despite these advantages, the testing procedure has obvious limitations as it can only be applied to bivariate systems and does not allow to test for $s>1$. This represents a significant restriction when we are dealing with a larger dataset. In the following section we propose an extension to the robust common feature analysis that would allow for more than one SCCF vector in higher order systems. Since the GMM approach is sensitive to the variable ordering and offers no size and power improvements when compared with canonical correlation tests, a CCA that is robust to heteroskedasticity is a more appropriate approach.

\subsection{Bootstrap}

\subsubsection{Simulations}

Based on the common factor representation (7) of the data, one could also use a bootstrap approach for the testing procedure. Similar to the trace statistic, this implies a sequential testing procedure using the pseudo-series reconstructed under each of the possible null hypothesis. The first step consists of obtaining estimates of the coefficient matrices in (7) after having correctly identified $s$. This is done by applying a reduced rank analysis based on canonical correlations. Following Centoni et al. (2007) we obtain the ML estimate of the SCCF matrix $\tilde{\beta}^{\prime}$ as the canonical variates of $\Delta y_{t}$ associated with the smallest $s$ eigenvalues $\lambda_{1}, \ldots, \lambda_{s}$. At the same time, matrix A represents the canonical variates of $W_{t-1}$ associated with the $n-s$ largest estimated eigenvalues, $\lambda_{s+1}, \ldots, \lambda_{n}$. Note that these are partial canonical correlations, after deterministic components such as constants and trends are netted out. We can obtain $\tilde{\beta}_{\perp}^{\prime}$ from an OLS regression of $\Delta y_{t}$ on $A^{\prime} W_{t-1}=F_{t-1}$.

In order to test the accuracy of the bootstrap procedure and its size properties when dealing with heteroskedasticiy, we have simulated a trivariate system of cointegrated variables $(r=1)$ with a SCCF structure. The DGP ( $p=2, r=1, s=2$ ) that we use to simulate the data is taken from Hecq et al. (2006).

$$
\left[\begin{array}{l}
\Delta x_{t} \\
\Delta y_{t} \\
\Delta z_{t}
\end{array}\right]=\left[\begin{array}{l}
-0.1 \\
-0.4 \\
-0.2
\end{array}\right]\left[\begin{array}{lll}
0 & 1 & -1
\end{array}\right]\left[\begin{array}{l}
x_{t-1} \\
y_{t-1} \\
z_{t-1}
\end{array}\right]+\left[\begin{array}{lll}
0.2 & 0.1 & 0.1 \\
0.8 & 0.4 & 0.4 \\
0.4 & 0.2 & 0.2
\end{array}\right]\left[\begin{array}{c}
\Delta x_{t-1} \\
\Delta y_{t-1} \\
\Delta z_{t-1}
\end{array}\right]+\left[\begin{array}{c}
\epsilon_{1 t} \\
\epsilon_{2 t} \\
\epsilon_{3 t}
\end{array}\right]
$$

The two linear combinations resulting in WN processes are defined by the following cofeature matrix:

$$
\tilde{\beta}^{\prime}=\left[\begin{array}{ccc}
1 & -0.25 & 0 \\
1 & 0 & -0.5
\end{array}\right]
$$

For $n=3$ and $s=2$, this implies that the matrix of short run dynamics is of reduced rank $n-s=1$. The linear combinations of $\Delta x_{t-1}, \Delta y_{t-1}$ and $\Delta z_{t-1}$ underlying the VECM structure are not linearly independent: the variables in the VECM have common dynamics and the dimension of the system can be further reduced without loss of information. This is extremely helpful when estimating large systems 
of equations as it significantly reduces the number of free parameters. In order to also test the null $s=1$ we must only adjust one entry the $\Gamma$ matrix such that, arbitrarily chosen, the second cofeature vector $\tilde{\beta}_{2}^{\prime}=[1,0,-0.5]$ no longer annihilates the short run dynamics.

We also introduce heteroscedasticity by following the multivariate constant GARCH correlation framework of Bollerslev (1990). We define the following structures:

$$
h_{i t}=\omega_{i}+\alpha_{i} \epsilon_{i t-1}^{2}+\beta_{i} h_{i t-1}, \quad \epsilon_{t}=u_{t} \bar{H}_{t}
$$

where

$$
H_{t}=D_{t} C D_{t}, \quad D_{t}=\operatorname{diag}\left(\sqrt{h_{i t}}\right), \quad C=\left[\begin{array}{ccc}
1 & 0.6 & 0.6 \\
0.6 & 1 & 0.6 \\
0.6 & 0.6 & 1
\end{array}\right]
$$

The error term is $\epsilon_{t}=\left(\epsilon_{1 t}, \epsilon_{2 t}, \epsilon_{3 t}\right)$ with $u_{i t}$ independent $\mathrm{N}(0,1)$ and $\bar{H}_{t}$ taken from the Cholesky decomposition of $H_{t}$. For the bootstrap procedure we use the data representation and the notations as described in equation (7).

$$
\Delta y_{t}=\tilde{\beta}_{\perp}^{\prime} A^{\prime} W_{t-1}+\epsilon_{t}
$$

As in the trace statistic case, the wild bootstrap has been shown to be appropriate when dealing with heteroscedasticity. It does however not correct for autocorrelation. The high rejection frequency obtained using the $\operatorname{GARCH}(1,1)$ system indicates that it is not appropriate to use asymptotic critical values. We perform a Monte Carlo analysis that incorporates a wild bootstrap procedure and returns mean rejection rates:

1. Create the DGP $Y_{t}=\left(x_{t}, y_{t}, z_{t}\right)$ as described above. Under the null of $s=\bar{s}$ obtain $\hat{A}$ and $\hat{\tilde{\beta}}_{\perp}^{\prime}$ and $\hat{\epsilon_{t}}$. Using the estimated residuals $\hat{\epsilon}_{t}$ and an independent $\mathrm{N}(0,1)$ sequence $\left\{w_{t}\right\}$ generate $\mathrm{T}$ bootstrap residuals $\epsilon_{t}^{b}=\hat{\epsilon}_{t} w_{t}$;

2. Reconstruct the bootstrap sample $Y_{t}^{*}$ using the bootstrapped residuals and the $\hat{A}$ and $\hat{\tilde{\beta}}_{\perp}^{\prime}$ obtained under the null. Store the SCCF statistic calculated from the pseudo-sample;

3. Repeat the first steps for each of the $B=999$ samples and calculate the bootstrap critical value $c_{10,5,1 \%}^{*}$. Store the rejection result by comparing the value of the test statistic of the original series to $c_{10,5,1 \%}^{*}$

4. In a Monte Carlo setting with $\operatorname{sim}=10000$ repeat steps 1 to 3 and calculate mean rejection frequencies at a specified significance level.

\subsubsection{Results}

We disregard the first 100 observations in order to analyze a system independent of its initial conditions. The results using asymptotic and bootstrap critical values with WN and GARCH errors are summarized 
in the following table. Note that this procedure is not pivotal and that the critical values depend on the sample parameters. As previously investigated by Candelon et al. (2005), the test for SCCF suffers from significant size distortions when the error process is not white noise. As the sample size gets large the rejection frequencies increase even further. We obtain significant improvements by using the bootstrap approach, with the empirical size very close to the $5 \%$ nominal one.

Table 9: Size properties using Asymptotic and Bootstrap 5\% critical values, $s=2$

\begin{tabular}{ccccccc} 
& \multicolumn{2}{c}{ WN } & \multicolumn{2}{c}{ GARCH $_{0.01,0.2,0.79}$} & \multicolumn{2}{c}{ GARCH $_{0.01,0.1,0.89}$} \\
\hline $\mathrm{T}$ & Size & Boot & Size & Boot & Size & Boot \\
50 & 0.093 & 0.058 & 0.158 & 0.060 & 0.115 & 0.050 \\
200 & 0.057 & 0.043 & 0.222 & 0.059 & 0.123 & 0.062 \\
500 & 0.052 & 0.046 & 0.347 & 0.054 & 0.165 & 0.056
\end{tabular}

Table 10: Power properties using Asymptotic and Bootstrap 5\% critical values, $s=2$

\begin{tabular}{ccc}
$\mathrm{T}$ & $\mathrm{GARCH}_{0.01,0.2,0.79}$ & $\mathrm{GARCH}_{0.01,0.1,0.89}$ \\
\hline 50 & 0.209 & 0.214 \\
200 & 0.669 & 0.648 \\
500 & 0.887 & 0.889
\end{tabular}

For the SF hypothesis, Tables 11,12,13 summarize results for the European bonds and compare the asymptotic critical values to comparable ones obtained by bootstrapping. We continue the testing and estimation section with the two subgroups previously mentioned (core and peripheral).

Table 11: Aut-Bel-Fr-Ned-Ger $(r=1, p=7, s=4)$

\begin{tabular}{ccccccc}
\hline $\mathrm{s}$ & $\lambda$ & stat & $\mathrm{df}$ & $\chi_{(d f)}^{2}$ & Boot 5\% & p-val \\
\hline 1 & 0.098 & 26.34 & 27 & 40.11 & 57.53 & 0.891 \\
2 & 0.191 & 80.23 & 56 & 74.46 & 107.86 & 0.444 \\
3 & 0.283 & 164.97 & 87 & 109.77 & 176.62 & 0.110 \\
4 & $0.355^{* *}$ & 276.69 & 120 & 146.56 & 271.30 & 0.039 \\
\hline
\end{tabular}

Table 12: PIIGS-Germany: PIIGSG $(r=2, p=11, s=4)$

\begin{tabular}{ccccccc}
\hline $\mathrm{s}$ & $\lambda$ & stat & $\mathrm{df}$ & $\chi_{(d f)}^{2}$ & Boot $5 \%$ & Boot p-val \\
\hline 1 & 0.314 & 84.2 & 57 & 75.61 & 111.46 & 0.423 \\
2 & 0.525 & 250.3 & 116 & 142.13 & 268.92 & 0.123 \\
3 & 0.631 & 472.6 & 177 & 209.04 & 492.55 & 0.101 \\
4 & $0.672^{*}$ & 721.2 & 240 & 277.14 & 744.13 & 0.081 \\
\hline
\end{tabular}


Table 13: Port-Ire-It-Esp-Ger: PIISG $(r=1, p=11, s=4)$

\begin{tabular}{ccccccc}
\hline $\mathrm{s}$ & $\lambda$ & stat & $\mathrm{df}$ & $\chi_{(d f)}^{2}$ & Boot $5 \%$ & Boot p-val \\
\hline 1 & 0.272 & 80.80 & 47 & 64.007 & 95.74 & 0.215 \\
2 & 0.347 & 189.20 & 96 & 119.88 & 206.94 & 0.143 \\
3 & 0.435 & 334.60 & 147 & 176.30 & 363.21 & 0.140 \\
4 & $0.529^{*}$ & 526.13 & 200 & 233.99 & 536.61 & 0.066 \\
\hline
\end{tabular}

Similar to the cointegration tests presented in the previous section, we can now draw some conclusions and compare the results obtained using asymptotic and bootstrap critical values. We first notice that for all of the country groups we now obtain much higher values for the SCCF space and, therefore, a significantly reduced number of "common cycles". The initial test statistics would imply no common features for the group of peripheral countries and Germany, i.e. $s=0$ and $n-s=n$. Results change drastically when we look at the bootstrapped p-vales. We find strong evidence for common short run movements, which support the concept of a monetary union with members responding similarly to shocks. A simple graphical analysis of the data in first differences strengthens the validity of our results. Except for some very large initial observations for countries like Greece we find almost a perfect overlap in month-to-month changes of sovereign yields.

\section{Estimation}

We now proceed with presenting the estimation results after having determined $s$ through the bootstrap testing procedure. Alternatively to using canonical variates for identifying the relevant linear combinations $\tilde{\beta}$, an efficient estimator is obtained using Full Information Maximum Likelihood (FIML). The FIML estimator is consistent and asymptotically normal without the normality assumption of the error term (Amemiya (1985)). Vahid and Engle (1993) also point out that LIML/FIML estimates are invariant to the normalization, in contrast to other IV/GMM approaches.

$$
B^{\prime} \Delta y_{t}=\left[\begin{array}{cccc}
0_{s * n} & 0_{s * n} & \ldots & 0_{r * n} \\
\Gamma_{21}^{*} & \Gamma_{22}^{*} & \ldots & \alpha
\end{array}\right] X_{t-1}^{*}+B^{\prime} \epsilon_{t}
$$

where $\Gamma_{2 i}^{*}$ represent the last $n-s$ rows of the VECM short-run parameter estimates and

$$
B^{\prime}=\left[\begin{array}{cc}
I_{s} & \tilde{\beta}_{s *(n-s)}^{*} \\
0_{(n-s) * s} & I_{n-s}
\end{array}\right]
$$

The cofeature matrix is $\tilde{\beta}^{\prime}=\left(I_{s} \tilde{\beta}_{s *(n-s)}^{*}\right)$. Notice that the first $s$ equations are normalized on the variables $\Delta y_{1 t}, \ldots, \Delta y_{s t}$. Such a normalization could allows for an easier interpretation of the relationships found while the standard errors obtained indicate if the estimates are statistically significant. We obtain matrices $\tilde{\beta}_{1}^{\prime}, \tilde{\beta}_{2}^{\prime}$ and $\tilde{\beta}_{3}^{\prime}$ for the three groups respectively (core, PIIGSG, PIISG). 


$$
\begin{gathered}
\tilde{\beta}_{1}^{\prime}=\left[\begin{array}{ccccc}
1 & 0 & 0 & 0 & -0.884^{* * *} \\
0 & 1 & 0 & 0 & -0.885^{* * *} \\
0 & 0 & 1 & 0 & -1.038^{* * *} \\
0 & 0 & 0 & 1 & -0.911^{* * *}
\end{array}\right] \\
\tilde{\beta}_{2}^{\prime}=\left[\begin{array}{cccccc}
1 & 0 & 0 & 0 & -0.927^{* * *} & 0.304 \\
0 & 1 & 0 & 0 & -0.616^{* * *} & -0.015 \\
0 & 0 & 1 & 0 & -1.030^{* * *} & 0.000 \\
0 & 0 & 0 & 1 & -0.799^{* * *} & 1.300^{* * *}
\end{array}\right] \quad \tilde{\beta}_{3}^{\prime}=\left[\begin{array}{ccccc}
1 & 0 & 0 & 0 & -0.669^{* * *} \\
0 & 1 & 0 & 0 & -0.899^{* * *} \\
0 & 0 & 1 & 0 & -0.836^{* * *} \\
0 & 0 & 0 & 1 & -0.998^{* * *}
\end{array}\right]
\end{gathered}
$$

For the group of core countries $(r=1, s=4)$ all the estimates are significant at the $1 \%$ level. The coefficients describing the $s=4$ linear combinations are very close to one. For the PIIGSG group with $r=2$ and $s=4$, the cofeature matrix is $\tilde{\beta}_{2}$. Disregarding Greece from the previous group $(r=1, s=4)$ we re-estimate the $\tilde{\beta}_{3}$ matrix. A Wald test on these coefficients rejects the null of $\tilde{\beta}_{i}=-1$ for Portugal. This result offers some more support against the stationarity of sovereign spreads w.r.t. Germany.

How much of the variance can be explained by the common cycle(s)? We can define the dynamics of the $(n-s)$ common cycles through the orthogonal complement of $\tilde{\beta}, \tilde{\beta}_{\perp}$. The percentage of variation explained is equivalent to the $R^{2}$ of the following OLS regression:

$$
\tilde{\beta}_{\perp} \Delta y_{t}=\alpha_{1}+\alpha_{2} \Delta y_{t-1}+\ldots+\alpha_{p-1} \Delta y_{t-p+1}+\epsilon_{t}
$$

Table 14: Aut-Bel-Fr-Ned-Ger $(n-s=1)$

\begin{tabular}{ccccc}
\hline Austria & Belgium & France & Germany & Netherlands \\
\hline 92.87 & 90.57 & 94.53 & 93.51 & 95.55 \\
\hline
\end{tabular}

Table 15: Port-Ire-It-Esp-Ger: PIISG $(n-s=1)$

\begin{tabular}{ccccc}
\hline Portugal & Ireland & Italy & Spain & Germany \\
\hline 78.86 & 60.43 & 65.66 & 68.17 & 43.39 \\
\hline
\end{tabular}

Table 16: PIIGS-Germany: PIIGSG cycle 1

\begin{tabular}{cccccc}
\hline Portugal & Ireland & Italy & Greece & Spain & Germany \\
\hline 53.36 & 65.06 & 71.37 & 29.52 & 84.99 & 55.71 \\
\hline
\end{tabular}

Table 17: PIIGS-Germany: PIIGSG cycle 2

\begin{tabular}{cccccc}
\hline Portugal & Ireland & Italy & Greece & Spain & Germany \\
\hline 47.41 & 32.74 & 20.73 & 84.12 & 29.29 & 12.89 \\
\hline
\end{tabular}


The core countries (Austria, Belgium, France, Germany, The Netherlands) represent a very compact group with one common "cycle" summarizing most of the variation. There is no heterogeneity in this first group. The situation changes when we move to the peripheral group and Germany. It is not surprising to find a very high explanatory power for Greece in the case of the second "cycle". Germany is, as expected, the outlier in this group while the rest of the countries follow a similar joint pattern (Portugal, Ireland, Italy and Spain).

We also calculate the $R^{2}$ of the OLS regression (22), i.e the percentage of variation in $\Delta y_{t}$ explained by $\tilde{\beta}_{\perp} \Delta y_{t}$. This allows us to calculate the cumulative explanatory power of multiple "cycles" which we are not able to do with the first regression setting (21). For the peripheral group of countries we compare the results from three different approaches: principal components analysis (PCA), asymptotic testing procedure, bootstrap. To keep results comparable, the PCA is performed on (stationary) first differences of the sovereign bond yields series.

$$
\Delta y_{t}=\alpha_{1}+\alpha_{2,3} \tilde{\beta}_{\perp} \Delta y_{t}+\epsilon_{t}
$$

Table 18: Aut-Bel-Fr-Ger-Ned $(n-s=1)$

\begin{tabular}{ccccc}
\hline Austria & Belgium & France & Germany & Netherlands \\
\hline 91.68 & 91.14 & 93.62 & 92.30 & 95.50 \\
\hline
\end{tabular}

Table 19: Port-Ire-It-Esp-Ger: PIISG $(n-s=1)$

\begin{tabular}{ccccccc}
\hline Method & Parameters & Portugal & Ireland & Italy & Spain & Germany \\
\hline PCA & $\mathrm{pc}=1$ & 54.64 & 65.06 & 72.05 & 79.05 & 54.82 \\
& $\mathrm{pc}=2$ & 97.93 & 66.76 & 84.21 & 86.39 & 55.13 \\
& $\mathrm{pc}=3$ & 99.08 & 95.30 & 94.26 & 86.71 & 71.89 \\
Asymptotic & $\mathrm{r}=4, \mathrm{~s}=0, \mathrm{n}-\mathrm{s}=5$ & 53.41 & 48.10 & 46.78 & 42.72 & 36.08 \\
Bootstrap & $\mathrm{r}=1, \mathrm{~s}=4, \mathrm{n}-\mathrm{s}=1$ & 73.59 & 48.77 & 66.99 & 68.70 & 40.03 \\
\hline
\end{tabular}

Note: Results based on $\Delta y_{t}=\alpha_{1}+\alpha_{2} \tilde{\beta}_{\perp} \Delta y_{t}+\epsilon_{t}$

Table 20: PIIGS-Germany: PIIGSG cumulative $(n-s=2)$

\begin{tabular}{cccccccc}
\hline Method & Parameters & Portugal & Ireland & Italy & Greece & Spain & Germany \\
\hline PCA & $\mathrm{pc}=1$ & 59.27 & 61.05 & 52.43 & 44.89 & 65.35 & 46.26 \\
& $\mathrm{pc}=2$ & 65.38 & 69.82 & 78.72 & 97.88 & 87.60 & 59.44 \\
& $\mathrm{pc}=3$ & 95.84 & 70.22 & 92.01 & 98.32 & 92.01 & 60.06 \\
Asymptotic & $\mathrm{r}=5, \mathrm{~s}=0, \mathrm{n}-\mathrm{s}=6$ & 71.65 & 63.83 & 58.44 & 61.38 & 51.34 & 45.53 \\
Bootstrap & $\mathrm{r}=2, \mathrm{~s}=4, \mathrm{n}-\mathrm{s}=2$ & 56.97 & 65.23 & 79.63 & 90.91 & 91.45 & 64.28 \\
\hline
\end{tabular}

Note: Results based on $\Delta y_{t}=\alpha_{1}+\alpha_{2,3} \tilde{\beta}_{\perp} \Delta y_{t}+\epsilon_{t}$ 
We observe again significant differences between the asymptotic and bootstrap results. For the PIISG group, cointegration and SCCF testing based on asymptotic critical value indicate $r=4$ and $s=0$ common feature vectors. The explanatory power of such a specification is the $R^{2}$ of the VECM. We now obtain a stronger common pattern, with the percentage of variation explained increasing significantly for Italy and Spain. These initial observations regarding the common behavior of sovereign yields offer strong support for our approach. When using asymptotic critical values we would conclude that at most $50 \%$ of the yield variation is explained by common driving factors. Correctly determining trends and cycles however leads us to identify a significantly stronger common behavior.

Adding Greece in the last group also offers some interesting results. Most percentages increase (notably Ireland, Italy, Spain) when comparing the PIISG to the PIIGSG groups. This can be interpreted as Greece adding a new link among these peripheral states. We could loosely read this result as a sign of contagion: the response of some countries is common when taking into account the yield movements of Greece. We also track the dynamics of the explanatory power in the following graphs to see if there are any major shocks. By keeping our identified $s$ and $\tilde{\beta}_{\perp}$ fixed, we start with the period $1990-1999$ and gradually add the rest of the sample for a dynamic perspective of the $R^{2}$. We also directly compare the PCA approach with our SCCF analysis. The two vertical lines indicate two major events in the financial market: the collapse of Lehman Brothers (Oct. 2008) and the launch of the Securities Market Programme (May 2010). Some observations regarding these graphs will be discussed in the following section.

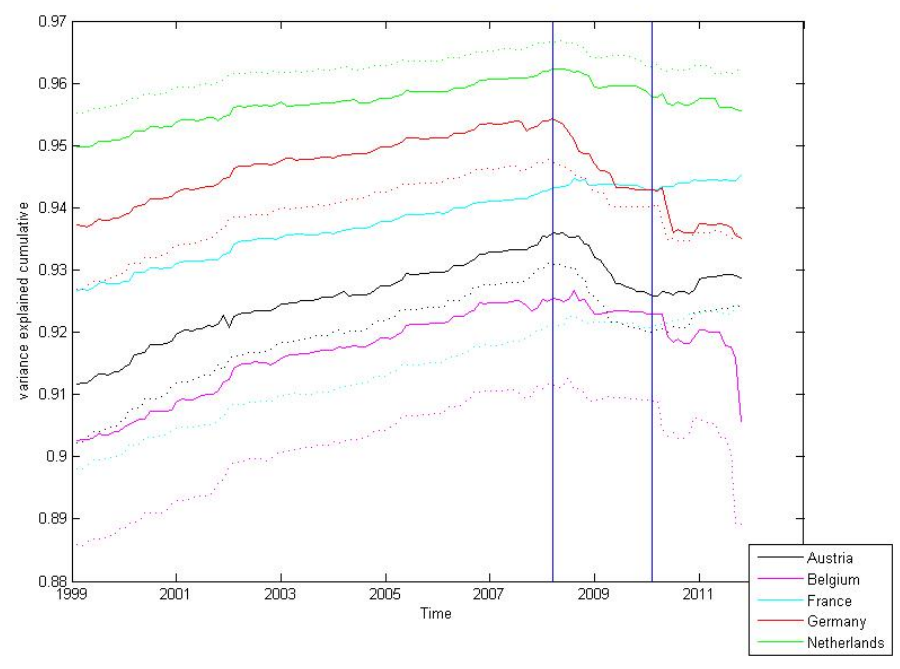

Figure 1: Variance explained PCA and SCCF core countries

Full line: $\tilde{\beta}_{\perp} \Delta y_{t}=\alpha_{1}+\alpha_{2} \Delta y_{t-1}+\ldots+\alpha_{p-1} \Delta y_{t-p+1}+\epsilon_{t} \quad$ Dotted line: $\Delta y_{t}=\theta_{1}+\theta_{2} P C_{1 t}+u_{t}$ 


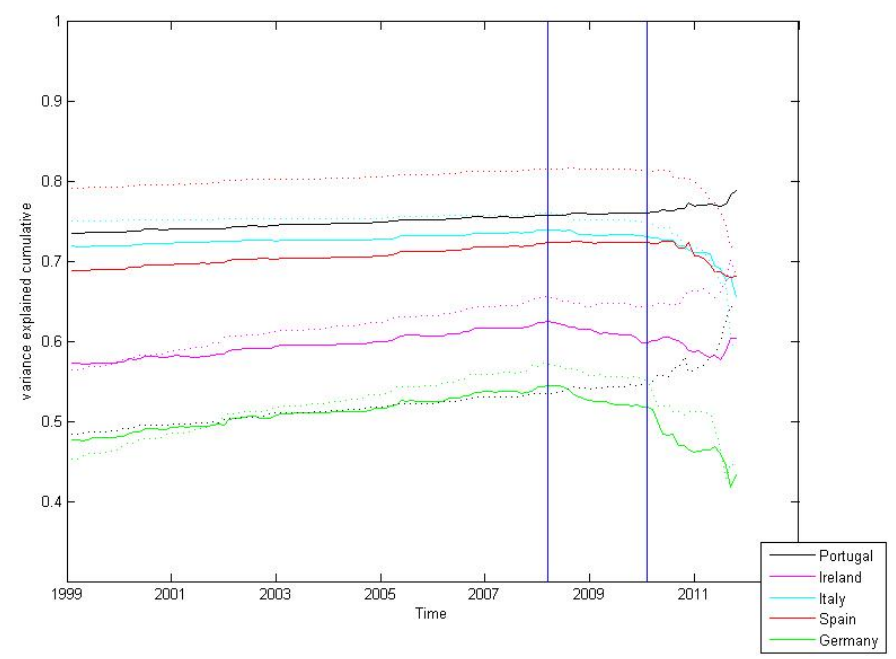

Figure 2: Variance explained PCA and SCCF PIIS-Germany

Full line: $\tilde{\beta}_{\perp} \Delta y_{t}=\alpha_{1}+\alpha_{2} \Delta y_{t-1}+\ldots+\alpha_{p-1} \Delta y_{t-p+1}+\epsilon_{t} \quad$ Dotted line: $\Delta y_{t}=\theta_{1}+\theta_{2} P C_{1 t}+u_{t}$

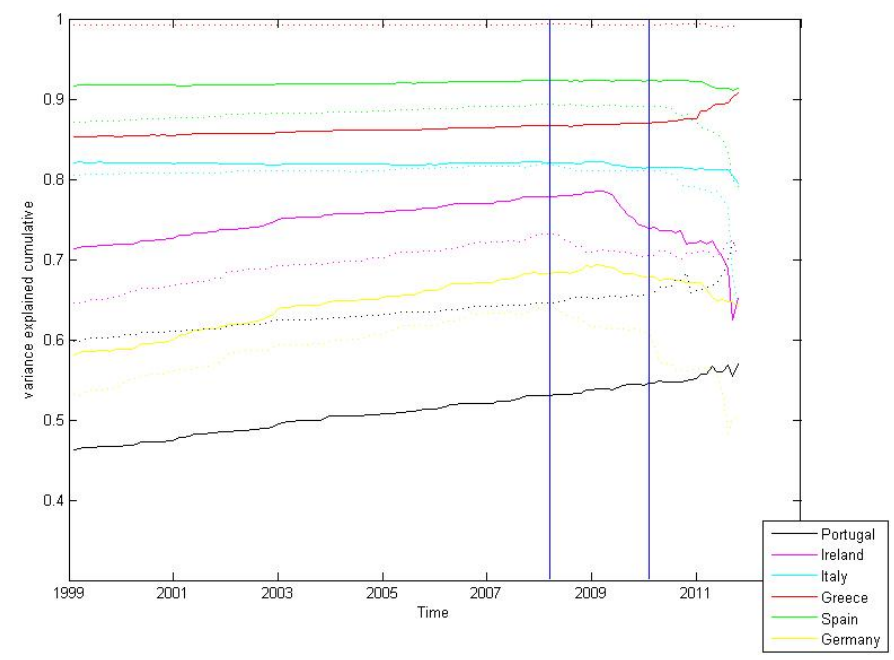

Figure 3: Variance explained PCA and SCCF PIIGS-Germany (cumulative)

Full line: $\Delta y_{t}=\alpha_{1}+\alpha_{2,3} \tilde{\beta}_{\perp} \Delta y_{t}+\epsilon_{t} \quad$ Dotted line: $\Delta y_{t}=\theta_{1}+\theta_{2} P C_{1 t}+\theta_{3} P C_{2 t}+u_{t}$

\section{Effect of the financial crisis}

The final graphs of the last subsection raise some concerns about the sensitivity of our results to the ongoing crisis. While the choice of our data frequency does not allow us to look separately at the crisis period, we can still observe variation in the explanatory power of common dynamics. We have repeated the analysis by eliminating the last subsample corresponding to general divergence. The exact sample size is mentioned in Table 21. Although we modify the sample size, we keep the values obtained for $r$ and $s$ from the full sample. Cointegration is a long-run concept and we do not expect the number of common 
stochastic trends to change when removing a relatively small number of observation (a trace test also confirms our intuition). Also, through the SCCF testing procedure we obtain even stronger support for our initial result of minimum number of "common cycles", i.e. $n-s=r$, when eliminating the last 3 years. This is also not surprising considering the strong convergence of yields up to the start of the crisis.

Table 21: Effect of 2008-2011 financial crisis

\begin{tabular}{|c|c|c|c|c|c|c|}
\hline Sample & Austria & Belgium & France & Germany & Netherlands & \\
\hline 1990:01-2008:08 & 93.53 & 92.49 & 94.28 & 95.39 & 96.16 & \\
\hline 1990:01-2011:09 & 92.87 & 90.57 & 94.53 & 93.51 & 95.55 & \\
\hline Sample & Portugal & Ireland & Italy & Spain & Germany & \\
\hline 1990:01-2008:08 & 75.80 & 62.33 & 73.99 & 72.33 & 54.35 & \\
\hline 1990:01-2011:09 & 78.86 & 60.43 & 65.66 & 68.174 & 39.46 & \\
\hline Sample & Portugal & Ireland & Italy & Greece & Spain & Germany \\
\hline 1990:01-2008:08 cumulative & 53.06 & 77.92 & 82.21 & 86.74 & 92.39 & 68.38 \\
\hline 1990:01-2011:09 cumulative & 56.97 & 65.23 & 79.63 & 90.91 & 91.45 & 64.28 \\
\hline
\end{tabular}

Note: Results based on $\tilde{\beta}_{\perp} \Delta y_{t}=\alpha_{1}+\alpha_{2} \Delta y_{t-1}+\ldots+\alpha_{t-p+1} \Delta y_{t-p+1}+\epsilon_{t}$

For the core countries group we can explain more than $90 \%$ of the variation throughout the sample. In Figure 1 and Table 21 we see a general decline towards the end of the period, most notably exactly around the time of the two events mentioned above. Considering the left hand scale in the graph this change is relatively small, probably reflecting concerns about significant exposures and contagion. We now move to the peripheral countries. The first observation that we can make, similarly to the previous section, is that most of the change in sovereign yields seems to be a result of common causes. When comparing the full sample with the one after taking out the crisis years we notice that most percentages do decrease slightly. The strongest change is found in the case of Germany. This is not surprising since there is clear divergence with respect to the core group of countries. On the other hand, for Portugal we can even see an increase in $R^{2}$. The introduction of Greece seems to add a new link among this set of countries. While a significant number of papers dealing with the recent widening of spreads and large yield changes argue for a fiscal profligacy origin and hence an idiosyncratic root, country data on fiscal balances and their evolution after 1999 does not offer enough support for such causality. While yield changes for Greece and other peripheral countries seem to be strongly correlated, the macroeconomic indicators of these countries do not fully sustain the idea of fundamental based weaknesses. There are instead signs of contagion and higher (general) risk aversion affecting all member states. We do not wish to negate the economic imbalances of these countries (Spain, Ireland, Portugal) but rather point out that a large percentage of these fiscal imbalances are rather the outcome of this crisis and not their direct origin (systemic vs. local causes). The figures describing the dynamic behavior of $R^{2}$ could also be informative about possible phases during the European sovereign debt crisis. Among peripheral countries (Figures 2 and 3), all observed decline in the degree of commovement is concentrated towards the very end of our sample. We suspect that, as the debt crisis has progressed, the source of distress has been 
gradually switching from increased global financial stress to concerns about aggravating weaknesses in the sovereign and banking sectors. We leave these very interesting questions for further research and plan to analyze the transmission of sovereign and banking distress in the Eurozone in a new working paper.

\section{Conclusion}

What drives the movements of sovereign bond yields in the Euro area? Can we talk about full convergence? From a statistical point of view, a convergence hypothesis in the Eurozone would imply that there is one (common) trend in the yields, i.e. a long run driving force. Economic intuition tells us that in a monetary union sovereign yields should react similarly to a common shock and that idiosyncratic characteristics should play a reduced role. A simple graphical analysis of yields shows a clear downward trend for a peripheral group of countries before 1999, a convergence to the low and more stable path of core members. Following a long period of almost no differentiation, the most recent years are characterized by divergence and increase in spreads relative to Germany.

In this paper we analyze short run and long run properties of sovereign yields and try to disentangle area wide versus country specific dynamics. We apply a cointegration-SCCF approach in order to separate the common driving trends and cycles. When using econometric techniques on financial time series, we usually depart from the strict assumptions underlying the testing procedure. In many cases, such misspecifications invalidate the results obtained. Heteroscedasticity is a common occurrence and not the exception to the rule when performing empirical studies and it should therefore be taken into account when estimating and performing inference. Even starting with the cointegration analysis we have dramatically different results then those based on tabulated critical values. When using a common movement analysis at a higher frequency, asymptotic test indicate $s=1$ for the core countries and, therefore, $n-s=4$ common cycles. However, a simple graphical analysis and correlations close to one show that the first differences are moving almost perfectly together, overlapping one another for the core member states. The peripheral countries also have strong common movements, although the fluctuations are not as strictly aligned as in the first group. Such overlapping behavior is a clear indication of a common cyclical pattern, which is exactly the result we obtain when bootstrapping the SCCF test statistic. We obtain a minimum number of common cycles $(r)$ for most of our groups. Greece seems to add a separate link when trying to disentangle the yields movements.

We choose to work with two separate groups, one containing Eurozone core countries and a second one with peripheral countries. We add Germany to the PIIGS group in order to analyze the dynamics of yields relative to what is commonly considered to be the benchmark for the common currency area. Since our results find strong comovement within the core countries, we believe that the Germany yield encompasses all the other sovereign interest rates and makes the second group specification appropriate for a common Eurozone analysis.

Our results for the two main groups of countries indicate that there are more than one driving stochastic trend and only one "cycle". We can attach economic interpretation to these findings: the long run movements of the bond yields are influenced by a series of macroeconomic and financial fundamental 
factors which are different for each country; on the other side, the cyclical variation is mostly common as the yields react very similarly to external shocks when countries are part of a monetary union.

Our results also raise questions regarding the stationarity of the spreads w.r.t. Germany. Neither the cointegration nor some of the SCCF matrix elements were equal to 1, indicating that one must be careful when assuming the stationarity of a $(1,-1)$ linear combination w.r.t. Germany. Such a relationship is usually imposed in most papers dealing with spreads dynamics and we avoid such problems by working with yields in levels and first differences.

The last subsample in our dataset allows us to investigate how sensitive our results are to the recent developments in the sovereign bond market. During periods of increased risk aversion, investors rebalance their portfolios and substitute risky assets for more creditworthy bonds ("flight to quality"). Most of the movement in the yields is common, even when taking into account the sovereign debt crisis period. When country specific factors can only explain a reduced proportion of the divergence w.r.t. Germany, we can conclude that there has been a shift in the way markets price risk and estimate default probabilities. Before 2008 we observed a rapid process of convergence, despite a weak link between this narrowing of spreads and fundamentals ("positive contagion"). We now detect a similar decoupling, working through comparable mechanisms but in the opposite direction. Understanding the relative contributions of common and idiosyncratic factors is also of interest for policymakers. If high borrowing costs are mainly due to increased general risk aversion, a rapid process of fiscal consolidation and austerity will only weaken even further the economy without bringing about the desired positive effects. We suspect that, as the debt crisis has progressed, the source of distress has been gradually switching from increased global financial stress to concerns about aggravating weaknesses in the sovereign and banking sectors. Further research should be directed at identifying these shifts in investors' attitude and their underlying causes. 


\section{References}

[1] Amemiya, T. (1985) Advanced Econometrics, Harvard University Press

[2] Anderson, H. M. \& Vahid, F. (2010) VARs, Cointegration and Common Cycle Restrictions, Monash Econometrics and Business Statistics WP No.14

[3] Ardagna, S., Caselli, F. \& Lane T. (2007) Fiscal Discipline and the Cost ofPublic Debt Service: Some Estimates for OECD Countries, The B.E. Journal of Macroeconomics: vol. 7(1), article 28

[4] Attinasi, M. G, Checherita, C. \& Nickel, C. What explains the surge in Euro Area Sovereign Spreads during the Financial Crisis of 2007-2009?, ECB Woking paper

[5] Beber, A., Brandt, M. W. \& Kavajecz, K. A. (2009) Flight-to-Quality or Flight-to-Liquidity? Evidence from the Euro-Area Bond Market, Review of Financial Studies, vol 22(3), 925-957

[6] Beveridge, S. \& Nelson C.R. (1981) A new approach to decomposition of economic time series into permanent and transitory components with particular attention to measurement of the "business cycle", Journal of Monetary Economics, vol. 7(2), 151-174

[7] Branco, J.A., Croux, C., Filzmoser, P. \& Oliviera, M. R. (2005) Robust Canonical correlations: A comparative study, Computational statistics, vol 20, 203-229

[8] Candelon, B., Hecq, A. \& Verschoor, W. (2005) Measuring Common Cyclical Features During Financial Turmoil, Journal of International Money and Finance, vol. 24, 1317-1334

[9] Cavaliere, G., Rahbeck, A. \&Taylor. A. M. R. (2010a) Co-integration Rank Testing under Conditional Heteroskedasticity, Econometric Theory, vol. 26(06), 1719-1760

[10] Cavaliere, G., Rahbeck, A. \&Taylor. A. M. R. (2010b) Bootstrap Sequential Determination of the Co-integration Rank in VAR Models, Creates research paper 2010-7

[11] Centoni, M., Cubadda, G. \& Hecq, A. (2007) Common shocks, common dynamics and the international business cycle, Economic Modelling, vol. 24(1), 149-166

[12] Cheung, Lai (1993) Finite-sample sizes of Johansen's likelihood ratio tests for cointegration, Oxford Bulletin of Economics and Statitsics, vol 55(3), 313-328

[13] Cheung, Yin-Wong \& Westermann, F. (2002) Output dynamics of the G7 countries- stochastic trends and cyclical movements, Applied Economics, vol. 34, 2239-2247

[14] Codogno, L., C. Favero \& A. Missale (2003) Yield Spreads on EMU Government Bonds, Economic Policy, vol. 18(37), 503532

[15] Cubadda, G. (1999) Common serial correlation and common business cycles: A cautious note, Empirical Economics, vol. 24(3), 529-535

[16] Ehrmann, M., Fratzscher, M., Güürkaynak, R. S. \& Swanson, E. T. (2011) Convergence and Anchoring of Yield Curves in the Euro Area, The Review of Economics and Statistics, vol. 93(1), 338-349 
[17] Engle, R. \& Kozicki, S. (1993) Testing for common features, Journal of Business and Economic Statitics, vol 11(4), 369-380

[18] von Hagen, S., Schuknecht, L. \& Wolswij, G. (2011) Government bond risk premiums in the EU revisited: The impact of the financial crisis, European Journal of Political Economy, vol. 27(1), 36:43

[19] Hansen, L. (1982) Large sample properties of generalized method of moments estimators, Econometrica, vol. 50(3), 1029-1054

[20] Hecq, A., Palm, F. C., \& Urbain, J. P. (2003) Common cyclical features analysis in VAR models with cointegration, Journal of Econometrics, vol. 132, 117-141

[21] Issler, J. V. \& Vahid, F. (1992) Common cycles in macroeconomics agregates, Journal of International Economics, vol. 17(1)

[22] Johansen, S. (1988) Statistical analysis of cointegrating vectors, Journal of Economic Dynamics and Control, vol. 12, 231-255

[23] Johansen, S. (1991) Estimation and hypothesis testing of cointegration vectors in Gaussian Vector Autoregressive Models, Econometrica, vol. 59(6), 1551-1580

[24] Johansen, S. \& Juselius, K. (1990) Maximum likelihood estimation and inference on cointegration with applications to the demand for money, Oxford Bulletin of Economics and Statistics, vol. 52(2), $169-210$

[25] Lindenberg, N. \& Westermann, F. (2009) Common Trends and Common Cylces among Interest Rates of the G7-Countries, CESifo Working Paper No. 2532

[26] Metiu, N. (2011) The EMU in debt distress: Contagion in sovereign bond markets, Working Paper

[27] Seo, B. (2007) Asymptotic distribution of the cointegrating vector estimator in error correction models with condition heteroskedasticity, Journal of Econometrics, vol. 137, 68-111

[28] Sgherri, S \& Zoli, E. (2009) Euro Area Sovereign Risk During the Crisis, IMF Working paper 222

[29] Swensen, A.R. (2006) Bootstrap algorithms for testing and determining the cointegration rank in VAR models, Econometrica, vol. 74, 1699-1714

[30] Vahid, F. \& Engle, R. F. (1993) Common trends and common cycles, Journal of Applied Econometrics, vol. 8(4), 341-360 


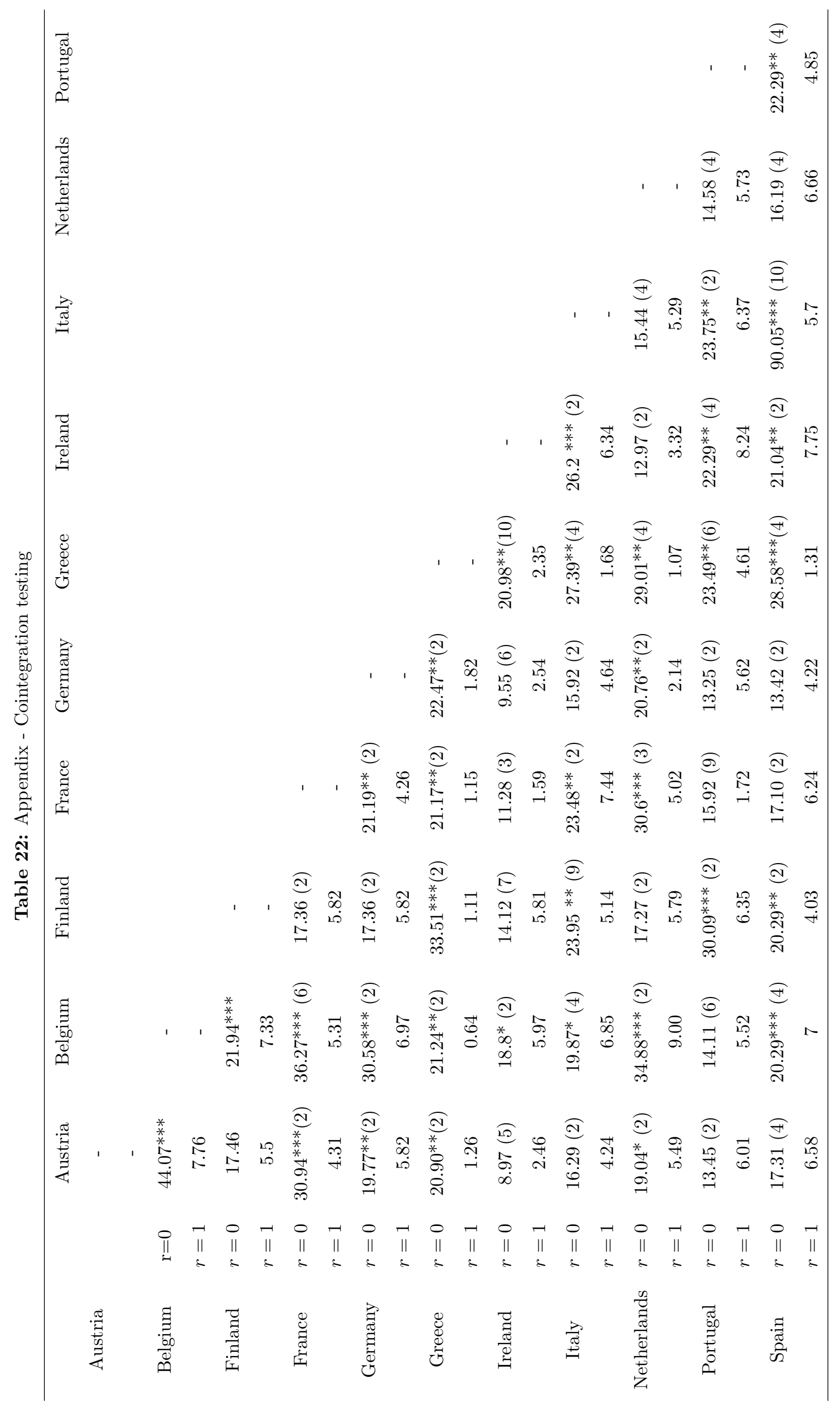

